\title{
The Disinfectant Effect of Modified Hydrothermal Nanotitania Extract on Candida albicans
}

\author{
Nor Farid Mohd Noor ${ }^{(D,},{ }^{1}$ Mohamad Ezany Yusoff, ${ }^{1}$ Mohd Azizi Abdul Rahman, ${ }^{2}$ \\ Mohammad Khursheed Alam $\mathbb{D}^{3},{ }^{3}$ and Ahmad Mukifza Harun $\mathbb{D}^{4}$ \\ ${ }^{1}$ School of Dental Science, Universiti Sains Malaysia, Health Campus, 16150 Kubang Kerian, Kelantan, Malaysia \\ ${ }^{2}$ Malaysia-Japan International Institute of Technology, Universiti Teknologi Malaysia, Jln. Sultan Yahya Petra, \\ 54100 Kuala Lumpur, Malaysia \\ ${ }^{3}$ College of Dentistry, Jouf University, Sakaka 72721, Saudi Arabia \\ ${ }^{4}$ Engineering Faculty, Universiti Malaysia Sabah, Jalan UMS, 88400 Kota Kinabalu, Sabah, Malaysia \\ Correspondence should be addressed to Nor Farid Mohd Noor; drfaid@usm.edu.my, \\ Mohammad Khursheed Alam; dralam@gmail.com, and Ahmad Mukifza Harun; mukifza@ums.edu.my
}

Received 22 December 2020; Revised 19 January 2021; Accepted 20 January 2021; Published 8 February 2021

Academic Editor: Rosario Caltabiano

Copyright ( 2021 Nor Farid Mohd Noor et al. This is an open access article distributed under the Creative Commons Attribution License, which permits unrestricted use, distribution, and reproduction in any medium, provided the original work is properly cited.

\begin{abstract}
Candida albicans is a pathogenic yeast typically associated with diseases such as HIV, AIDS, and other immunocompromised conditions. It is rarely the cause of fatalities and is commonly treated with drugs administered orally or intravenously. In this experiment, Candida albicans was tested with an extract of modified hydrothermal nanotitania to identify whether the material is capable of inhibiting the organism's growth. The extract was mixed with the Candida albicans in a culture media preparation to determine whether the organisms were able to grow. The test showed that modified hydrothermal nanotitania inhibits the growth of this organism.
\end{abstract}

\section{Introduction}

A fungus is a common single-celled or eukaryotic organism. In the fungal community, the most commonly found dimorphic type is Candida albicans. It frequently causes various local medical infections of the nails, vagina (vaginitis), and respiratory system. Candida infection or candidosis rarely occurs spontaneously as it needs favourable conditions for growth. Those patients most prone to developing candidosis are those receiving broad-spectrum antibiotics and those with diabetes mellitus. In these groups, candida develops in the saliva [1]. Other factors that can lead to candidosis are the suppression of the immune system through, for example, immunodeficiency viral infection, and the loss of skin integrity, as in the case of eczema. In certain instances, candidosis may be preceded by a fever of unknown origin leading to systemic fungal infection [2].
Treatment of candidosis is via local ointment or oral antifungal depending on the type of infection. Drugs such as amphotericin B and caspofungin are commonly used to treat the condition [3]. Certain antibiotics, such as rapamycin, are also used [4].

Unfortunately, candida can sometimes be resistant to antifungal treatment. For example, candidosis in the oropharynx has been reported as being resistant to fluconazole [5]. It is speculated that this drug resistance is due to genetics $[6,7]$. In another study, candida was found to have the ability to form a biofilm which may contribute to antifungal resistance [8]. This biofilm could in fact be a multifactorial mechanism according to research conducted using an efflux pump [9]. Another hypothesis relating to biofilm resistance is that the changes in sterol composition with altered membrane permeability transform antifungals into candida [10]. 
TABLE 1: Monitoring of Candida albicans growth on tested agar at 24-, 48-, and 72-hour intervals.

\begin{tabular}{|c|c|c|c|}
\hline Test/hours of incubation & 24 hours & 48 hours & 72 hours \\
\hline Candida only (negative control) & Growth & Growth & Growth \\
\hline Undoping (positive control) + candida & No growth & No growth & No growth \\
\hline $\mathrm{TiO}_{2}$ with $0.01 \%$ silver + candida & No growth & No growth & No growth \\
\hline $\mathrm{TiO}_{2}$ with $0.03 \%$ silver + candida & No growth & No growth & No growth \\
\hline $\mathrm{TiO}_{2}$ with $0.05 \%$ silver + candida & No growth & No growth & No growth \\
\hline
\end{tabular}

The surface roughness of titanium dental implants has been associated with the significant resistant properties of Candida albicans [11]. In an experiment, Streptococcus mutans was combined with Candida albicans biofilm, and corrosion of the titanium was observed due to $\mathrm{pH}$-lowering [12]. These two organisms-Streptococcus mutans and Candida albicans - were both able to produce biofilm in vivo and invitro [13]. As with Streptococcus mutans, Candida albicans also facilitates Staphylococcus aureus in systemic infection [14]. The biofilm development on titanium was reduced by covalently binding it with vancomycin and caspofungin [15]. Interestingly, candida did not produce the same results on zirconia ceramic implants [16].

Nanotitanium dioxide (nanotitania) has been successfully extracted via a modified hydrothermal process [1719]. It is well-known that titanium dioxide has a low energy band gap which enables excited electrons to jump from the valance band to the conduction band and to also easily perform photocatalytic activities. The manipulation of these low band gap activities has been performed in previous studies of dye-sensitized solar cells [20,21]. Titanium dioxide $\left(\mathrm{TiO}_{2}\right)$ is currently being used against bacterial invasion. A reduction in $E$. coli development was precipitated by gradually increasing the concentration of $\mathrm{TiO}_{2}$ nanoparticles used [22]. In other research, the combination of $\mathrm{TiO}_{2}$ with silver was found to act as antimicrobial material [23]. Furthermore, naturally produced synthesized $\mathrm{TiO}_{2}$ nanoparticles extracted from the Psidium guajava aqueous leaf are connected with their antibacterial action against S. aureus, Pseudomonas aeruginosa, and Escherichia coli [24].

The mechanism utilised by titanium dioxide to stop bacterial activity has been the subject of several experiments. Nanoparticles of $\mathrm{TiO}_{2}$ have been shown to inhibit the growth of the bacteria Streptococcus mutans orally through the suppression of the 24-hour lactate production mechanism [25]. In addition, $\mathrm{TiO}_{2}$-based nanocomposite when used for its photocatalytic properties reduces the expression of specific genes and proteins in P. aeruginosa PAO1 cells [26].

In this study, Candida albicans was combined with a nanotitania extract, which had been modified hydrothermally to detect whether nanotitania has the ability to reduce and/or eliminate organisms. During the experiment, the modified hydrothermal nanotitania extract was mixed together with the organisms in culture media to determine the organism's growth potential.

This study is expected to show similar results as those obtained from our previous test of modified hydrothermal nanotitania extract which revealed inhibition of Staphylo- coccus aureus and E. coli growth [27, 28]. Previous experiments with nanotitanium dioxide have also resulted in suppressing its mutagenic capability [29] and also its toxicological properties [30].

The findings of this study are that nanotitania extract when modified hydrothermally and combined with nanoparticles and a high percentage of silver is able to resist the growth of Candida albicans.

\section{Materials and Methods}

Hydrothermally modified nanotitania extract was mixed with multiple concentrations of silver $(0.01 \%, 0.03 \%$, and $0.05 \%)$ in a test plate. To test these materials, a control of titanium dioxide was used without any silver mixing (undoped). One of the key aspects of the nanotitania to note is it was not diluted in water, dimethyl sulfoxide (DMSO), or sulphuric acid.

A sample of Candida albicans was obtained from a hospitalized patient at Hospital Universiti Sains Malaysia which was then grown in the microbiology lab of the School of Medical Sciences, Universiti Sains Malaysia.

The test was done to monitor whether the nanotitania extract was able to prevent the growth of the bacteria and fungus by mixing it with the agar media before the addition of the bacteria/fungus (the method used by Ahmad et al., 2013 [17]). In addition, a control media without the nanotitania extract was used in which the candida was allowed to grow.

2.1. Preparation of $\mathrm{TiO}_{2}$. Suspensions of $1 \mathrm{~g} / \mathrm{ml} \mathrm{TiO}_{2}$ (together with $0.01 \%, 0.03 \%$, and $0.05 \%$ silver) and undoped (plus a positive control containing $\mathrm{TiO}_{2}$ and no silver) were prepared by mixing $1 \mathrm{~g}$ of $\mathrm{TiO}_{2}$ in $1 \mathrm{ml}$ of Mueller Hinton Broth $(\mathrm{MH})$ before the addition of $1 \mathrm{ml} \mathrm{E}$. coli equivalent $0.5 \mathrm{MacFaland}$. Agar containing only bacteria without $\mathrm{TiO}_{2}$ was used as a negative control. The suspensions were then placed in an incubator with a shaker for 24 hours at a temperature of $37^{\circ} \mathrm{C}$. A $100 \mu$ l suspension was inoculated on $\mathrm{MH}$ agar, and the bacterial inoculation was spread with a hockey stick. The agar plates were observed after 24, 48, and 72 hour incubation periods to detect any bacterial growth.

Candida albicans was prepared on an agar plate (using the method mentioned above in (a)). After 24 hours of incubation, the agar plate containing the bacteria was checked for evidence of growth. The $\mathrm{TiO}_{2}$ containing $0.01 \%, 0.03 \%$, and $0.05 \%$ silver and undoped (containing $\mathrm{TiO}_{2}$ only) were weighed on the analytical balance digital precision electronic scale for 1 gram each. The substances then were added and distributed on the prepared agar plate containing the growth 


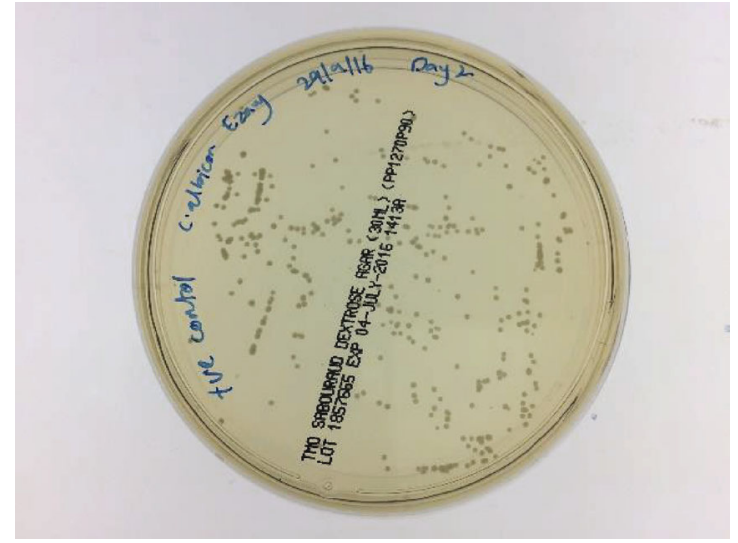

(a)

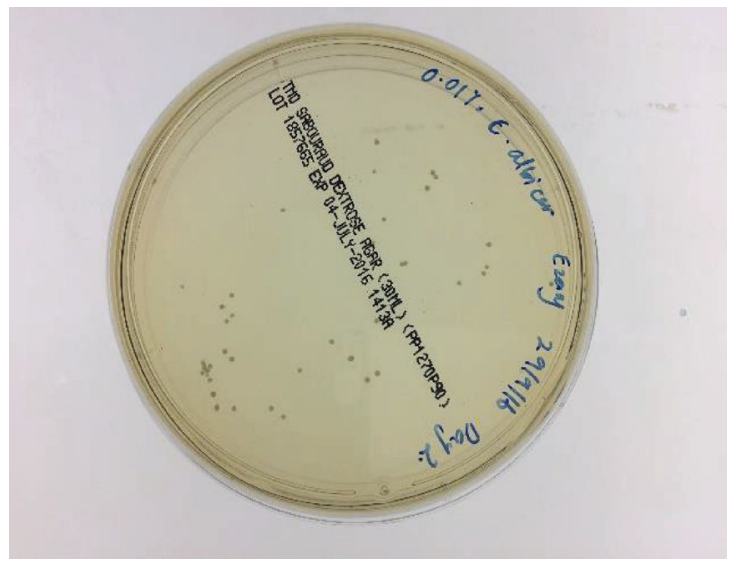

(c)

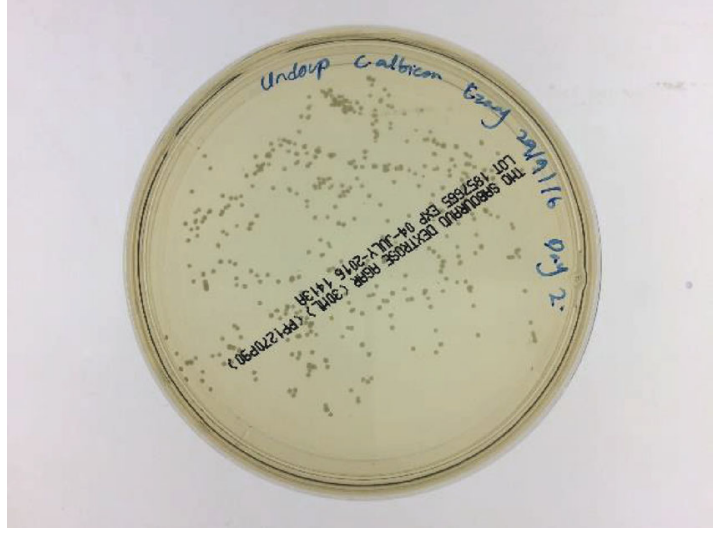

(b)

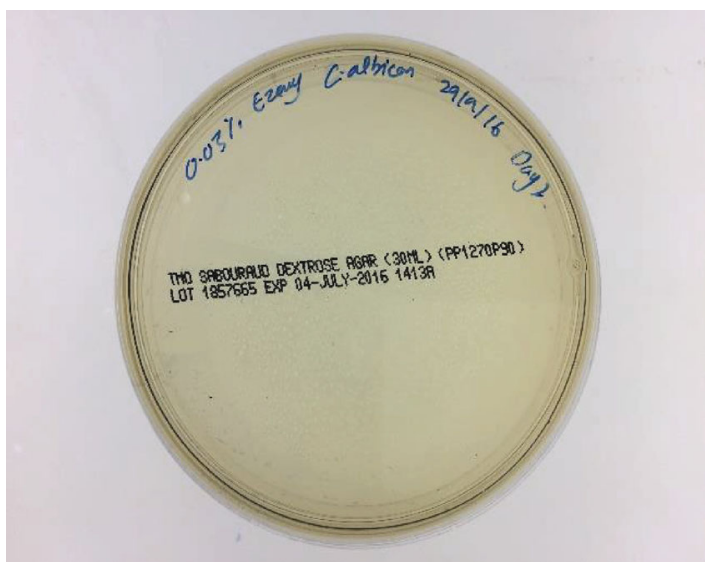

(d)

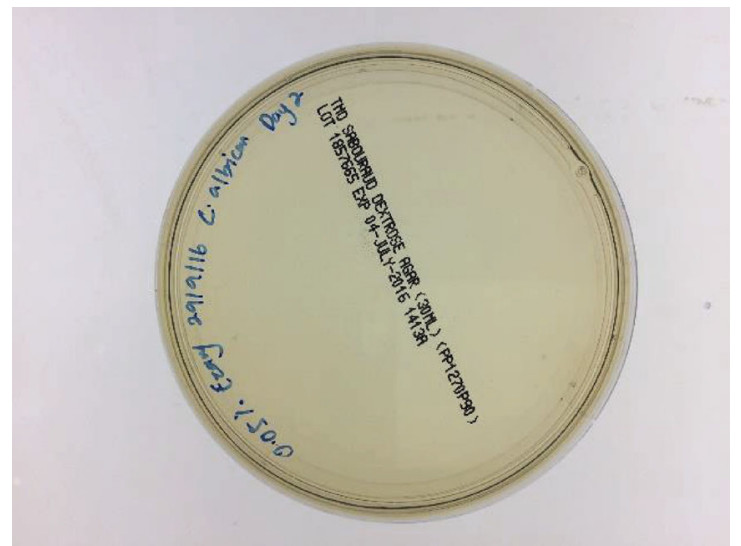

(e)

FIgure 1: Testing modified hydrothermal nanotitania extract with Candida albicans: (a) control media-containing candida only; (b) TiO only; (c) $\mathrm{TiO}_{2}$ containing $0.01 \%$ silver with candida; (d) $\mathrm{TiO}_{2}$ containing $0.03 \%$ silver with candida; (e) $\mathrm{TiO}_{2}$ containing $0.05 \%$ silver with candida. Note: no Candida albicans growth was detected in the agar plates (d) and (e). However, agar plate (c) contained a significantly smaller candida colony.

bacteria (one substance on one plate containing the bacteria) under the fume hood (room temperature). A plate containing the bacteria was used as a control under the same conditions. The plates were each observed for changes in morphology. Specifically, changes in shape, size, colour, plus any other differences were noted and times recorded with the aid of a stopwatch.

\section{Results and Discussion}

Modified hydrothermal nanotitania extract containing titanium dioxide $\left(\mathrm{TiO}_{2}\right)$ mixed with $0.01 \%, 0.03 \%$, and $0.05 \%$ silver nanoparticles and "titanium dioxide only" is more capable of stopping the growth of Candida albicans than the control media. 
Titanium dioxide $\left(\mathrm{TiO}_{2}\right)$ comprising silver concentrations at various percentages $(0.01 \%, 0.03 \%$, and $0.05 \%)$ and $\mathrm{TiO}_{2}$ only are able to inhibit the growth of Candida albicans on an agar plate in comparison to a control containing no nanoparticles. In various agars containing the nanotitania extract consisting of modified hydrothermal nanotitania extract mixed with silver (at $0.01 \%, 0.03 \%$, and $0.05 \%$ concentrations), no Candida albicans growth was observed after 24,48 , or 72 hours. In the negative control agar without the nanotitania extract, bacterial growth was noted. The results are shown in Table 1 incorporation with Figure 1.

\section{Discussion}

The deterrence of Candida albicans development in the oral cavity and other parts of the body is vital. Susceptibility to candidosis infection, as often noted in HIV and AIDS patients, has been the catalyst for research into Candida albicans prevention.

In this experiment, modified hydrothermal nanotitania extract containing $\mathrm{TiO}_{2}$ was mixed with differing percentages of silver $(0.01 \%, 0.03 \%$, and $0.05 \%)$ together with an undoped sample (containing $\mathrm{TiO}_{2}$ only) that were tested against Candida albicans. The main objective was to investigate the capability of this modified hydrothermal nanotitania extract to prevent the Candida albicans growth.

The main problem with the nanotitania extract was its inability to be diluted in water, dimethyl sulfoxide (DMSO), or sulphuric acid. In this experiment, the method used to identify the ability of these substances to prevent the growth of Candida albicans was the same one as used by Ahmad et al., 2013 (mentioned above). The results showed that the modified hydrothermal nanotitania extract can retain antifungal properties for up to 72 hours after addition to the agar containing the extract and the organisms. These results explain the potential of these substances to be used for at least 72 hours as antibacterial and antifungal agents.

4.1. Limitations of the Study. The modified hydrothermal nanotitania extract was not dissolved in water. This limited the range of tests possible for antibacterial properties.

\section{Conclusions}

In our experiment, the modified hydrothermal nanotitania extract was shown to inhibit the growth of Candida albicans.

\section{Data Availability}

Details are presented within the article in the form of tables and text in results. Other data will be made available upon request.

\section{Conflicts of Interest}

The authors declare no conflict of interest.

\section{Acknowledgments}

The authors would like to acknowledge Mr. Zawdy Badruddin (School of Dental Sciences, USM Health Campus) for the photos taken.

\section{References}

[1] L. Knight and J. Fletcher, "Growth of Candida albicans in saliva: stimulation by glucose associated with antibiotics, corticosteroids, and diabetes mellitus," The Journal of Infectious Diseases, vol. 123, no. 4, pp. 371-377, 1971.

[2] M. S. Gottlieb, R. Schroff, H. M. Schanker et al., "Pneumocystis carinii pneumonia and mucosal candidiasis in previously healthy homosexual men," New England Journal of Medicine, vol. 305, no. 24, pp. 1425-1431, 1981.

[3] J. Mora-Duarte, R. Betts, C. Rotstein et al., "Comparison of caspofungin and amphotericin B for invasive candidiasis," New England Journal of Medicine, vol. 347, no. 25, pp. 2020 2029, 2002.

[4] S. N. Sehgal, H. Baker, and C. Vézina, "Rapamycin (AY22,989), a new antifungal antibiotic. II. Fermentation, isolation and characterization," The Journal of Antibiotics, vol. 28, no. 10, pp. 727-732, 1975.

[5] L. Millon, A. Manteaux, G. Reboux et al., "Fluconazole-resistant recurrent oral candidiasis in human immunodeficiency virus-positive patients: persistence of Candida albicans strains with the same genotype," Journal of Clinical Microbiology, vol. 32, no. 4, pp. 1115-1118, 1994.

[6] L. E. Cowen, D. Sanglard, D. Calabrese, C. Sirjusingh, J. B. Anderson, and L. M. Kohn, "Evolution of drug resistance in experimental populations of Candida albicans," Journal of Bacteriology, vol. 182, no. 6, pp. 1515-1522, 2000.

[7] L. E. Cowen, A. Nantel, M. S. Whiteway et al., "Population genomics of drug resistance in Candida albicans," Proceedings of the National Academy of Sciences, vol. 99, no. 14, pp. 92849289, 2002.

[8] J. Chandra, D. M. Kuhn, P. K. Mukherjee, L. L. Hoyer, T. McCormick, and M. A. Ghannoum, "Biofilm formation by the fungal pathogenCandida albicans: development, architecture, and drug resistance," Journal of Bacteriology, vol. 183, no. 18 , pp. 5385-5394, 2001.

[9] G. Ramage, S. Bachmann, T. F. Patterson, B. L. Wickes, and J. L. López-Ribot, "Investigation of multidrug efflux pumps in relation to fluconazole resistance in Candida albicans biofilms," Journal of Antimicrobial Chemotherapy, vol. 49, no. 6, pp. 973-980, 2002.

[10] P. K. Mukherjee, J. Chandra, D. M. Kuhn, and M. A. Ghannoum, "Mechanism of fluconazole resistance in Candida albicans biofilms: phase-specific role of efflux pumps and membrane sterols," Infection and Immunity, vol. 71, no. 8, pp. 4333-4340, 2003.

[11] C. Tsang, H. Ng, and A. McMillan, "Antifungal susceptibility of Candida albicans biofilms on titanium discs with different surface roughness," Clinical Oral Investigations, vol. 11, no. 4, pp. 361-368, 2007.

[12] J. C. M. Souza, M. Henriques, R. Oliveira, W. Teughels, J.-P. Celis, and L. A. Rocha, "Do oral biofilms influence the wear and corrosion behavior of titanium?," Biofouling, vol. 26, no. 4, pp. 471-478, 2010.

[13] M. L. Falsetta, M. I. Klein, P. M. Colonne et al., "Symbiotic relationship between Streptococcus mutans and Candida 
albicans synergizes virulence of plaque biofilms in vivo," Infection and Immunity, vol. 82, no. 5, pp. 1968-1981, 2014.

[14] L. M. Schlecht, B. M. Peters, B. P. Krom et al., "Systemic Staphylococcus aureus infection mediated by Candida albicans hyphal invasion of mucosal tissue," Microbiology, vol. 161, no. 1, pp. 168-181, 2015.

[15] S. Kucharíková, E. Gerits, K. De Brucker et al., "Covalent immobilization of antimicrobial agents on titanium prevents Staphylococcus aureus and Candida albicans colonization and biofilm formation," Journal of Antimicrobial Chemotherapy, vol. 71, no. 4, pp. 936-945, 2015.

[16] R. Bürgers, S. Hahnel, T. E. Reichert et al., "Adhesion of Candida albicans to various dental implant surfaces and the influence of salivary pellicle proteins," Acta Biomaterialia, vol. 6, no. 6, pp. 2307-2313, 2010.

[17] H. Awang, A. Mukifza, S. Yusof, C. Ongkudon, and E. M. Farid, "Effect of acid concentration and time on synthesizing the titanium dioxide from synthetic rutile waste," International Journal of Recent Research in Physics and Chemical Science, vol. 3, pp. 60-66, 2017.

[18] A. M. Harun, S. Yusof, and H. Awang, "Experimental analysis of titanium dioxide synthesis from synthetic rutile waste using a moderate acid concentration and temperature," Acta Physica Polonica A, vol. 132, no. 3, pp. 833-835, 2017.

[19] A. Mukifza, H. Awang, and S. Yusof, "Synthesis and characterization of titanium dioxide using a caustic hydrothermal with moderate molarity and ratio from synthetic rutile waste," European Journal of Science and Technology, vol. 4, no. 8, pp. 127-130, 2016.

[20] M. J. Jimmy, A. M. Harun, M. Y. A. Rahman, and N. A. Ludin, "Comparative study of dye sensitized solar cell utilizing seaweed and rose Bengal sensitizer: influence of dye concentration," International Journal of Electrochemical Science, vol. 15, pp. 3219-3231, 2020.

[21] V. G. Martin, A. M. Harun, and M. Y. A. Rahman, "Dye sensitized solar cell utilizing Degaussa P25 and anatese $\mathrm{TiO}_{2}$ films: comparative study of photovoltaic performance: effect of N719 dye concentration," International Journal of Electrochemical Science, vol. 15, pp. 1643-1654, 2020.

[22] R. Ahmad and M. Sardar, " $\mathrm{TiO}_{2}$ nanoparticles as an antibacterial agent against E. coli," International Journal of Innovative Research in Science, Engineering and Technology, vol. 2, pp. 3569-3574, 2013.

[23] F. Martinez-Gutierrez, P. L. Olive, A. Banuelos et al., "Synthesis, characterization, and evaluation of antimicrobial and cytotoxic effect of silver and titanium nanoparticles," Nanomedicine, vol. 6, no. 5, pp. 681-688, 2010.

[24] T. Santhoshkumar, A. A. Rahuman, C. Jayaseelan et al., "Green synthesis of titanium dioxide nanoparticles using Psidium guajava extract and its antibacterial and antioxidant properties," Asian Pacific Journal of Tropical Medicine, vol. 7, no. 12, pp. 968-976, 2014.

[25] A. Besinis, T. De Peralta, and R. D. Handy, "The antibacterial effects of silver, titanium dioxide and silica dioxide nanoparticles compared to the dental disinfectant chlorhexidine on Streptococcus mutans using a suite of bioassays," Nanotoxicology, vol. 8, no. 1, pp. 1-16, 2014.

[26] A. Kubacka, M. S. Diez, D. Rojo et al., "Understanding the antimicrobial mechanism of $\mathrm{TiO}_{2}$-based nanocomposite films in a pathogenic bacterium," Scientific Reports, vol. 4, article 4134, 2014.
[27] N. F. M. Noor, A. M. Harun, S. Yusof, M. E. Yusoff, and S. Mohamad, "Effects of modified hydrothermal nanotitania on the viability of Staphylococcus aureus," Archives of Orofacial Science, vol. 13, no. 1, pp. 1-5, 2018.

[28] A. Mukifza, F. M. Nor, and I. Yusof, "The result of modified hydrothermal nanotitania extract to the Escherichia coli (E. coli) growth," Bangladesh Journal of Medical Science, vol. 19, no. 4, pp. 705-709, 2020.

[29] A. M. Harun, N. B. A. Ghani, N. F. M. Noor, R. Abas, and M. K. Alam, "Mutagenic properties of modified hydrothermal nanotitania extract," Bangladesh Journal of Medical Science, vol. 19, no. 1, 2020.

[30] A. M. Harun, N. F. M. Noor, R. Shaari, L. X. Ying, M. E. Yusoff, and M. K. Alam, "The toxicology properties of modified hydrothermal nanotitania extraction," Archives of Medical Science, pp. 1-4, 2021. 